Journal of Applied Pbilosophy, 11/2 (1994), 171-180. As "Deconstructing Disney World," translated into Chinese by Niu Hong Bao and published in Wen_She Zhe (Literature, History, and Philosophy, a journal in P.R. China), 1994/2, 92-103. Reprinted under the title "Deconstructing Disney World" in The Aesthetics of Human Environments, edited by Arnold Berleant and Allen Carlson (Peterborough, Ont: Broadview, 2007), pp. 139-149.

Arnold Berleant

\title{
THE CRITICAL AESTHETICS OF DISNEY WORLD
}

It might seem strange to propose an aesthetic consideration of the theme park, that artificial bloom in the garden of popular culture. ${ }^{1}$ The aesthetic is often considered a minority interest in the modern world, yet it offers a distinctive perspective, even on an activity that has mass appeal, and can provide insights that would otherwise remain undiscovered. Aesthetic description and interpretation can illuminate the theme park in many directions: as architecture, design, theater, landscape architecture, environment. I shall choose the last of these, environment.

Nominally, a theme park is a combination amusement park and world's fair, a place where people forget their cares and enjoy leisurely diversion in garden-like surroundings. Its relaxed, secure atmosphere is a marked change from the public places we frequently inhabit, such as the work place, the market, and the thoroughfare. At the same time, theme parks are complex palaces of delight that offer an extravagant variety of multi-sensory activities and experiences, and even purport to be educational. They are places of mass entertainment, easy to enter and enjoy, whose sounds and sights engulf us as soon as we pass through the gate. The concept of themeing is an environmental approach to the concept of place; taken collectively, theme parks constitute a multiplicity of environments, each playing its own tune.

Disney World collects many of these themes into one enormous "fantasia," a composite of disparate types from various sources--futuristic, ethnic, fantasy, adventure. It is a true anthology

1 This is a modified version of an essay that will appear in Theme Parks and Themed Places, ed. M. J. King (Popular Press, forthcoming). It owes much to Margaret J. King. I am also grateful to my colleagues José Reissig, David Sprintzen, and Michael Shodell for their valuable insights. The assistance of my wife, Riva Berleant-Schiller, has, as always, been incalculable. 
of distinctive environments. In its enormous variety, Disney World might be considered a microcosm of America's cultural pluralism; on the contemporary scene it stands as the kitsch of postmodernism. Yet its meanings do not lie wholly on the surface. Disney World invites a range of interpretations that parallels its postmodern ethos, making it at the same time an endlessly fertile subject for the subtextual elaborations of deconstruction. Like some of its rides whose sights appear abruptly out of the darkness, the rich significance of Disney World's environments appears on multiple levels and in strange juxtapositions. By exploring some of its multiple facets through an aesthetic analysis, I hope to uncover some unusual dimensions of Disney World's character as a postmodern environment. And deconstructing some of its multiple meanings will not only disclose its powerful normative message but inform a moral judgment as well.

\section{Disney World as an Aesthetic Environment}

Theme parks are totally constructed environments whose character is decided largely by their prominent aesthetic features. By aesthetic features I mean the perceptual dimensions through which we experience an environment directly--what we hear, see, and feel with our bodies as we move through it, and how these sensory qualities combine with our knowledge and beliefs to create a unified experiential situation.

Part of what determines an environment is the perceptual horizon that defines its boundaries. Disney World achieves this architecturally. Each area is stylistically coherent internally and distinctive externally. The three main divisions of Disney World: Magic Kingdom, Epcot Center, and Disney-MGM Studios, are separated physically from each other and delimited by definite borders punctuated by an entrance gate. Each division, in turn, breaks up into distinct areas defined by architectural style and color. In the Magic Kingdom, for example, the rustic structures of Frontierland are brown, the modernistic buildings of Tomorrowland are pink, while the green of tropical trees and plantings supports the wilderness character of Adventureland. The location and limits of each area, moreover, are clear. Dominant landmarks signal its center, while sharp shifts in the prevailing color and architecture form invisible lines that separate it from 
neighboring ones. Epcot Center has two major sections, Future World and World Showcase, within each of which are pavilions housing different kinds of scientific technology or distinct national enclaves. Although each of these stands separately, garden pathways connect them, and miniature trains, buses, boats, and a monorail assist travel from one area to another. Disney-MGM Studios also has two divisions: the studio and production section, and the various set locations and entertainment features. In all three parks, each area or building offers us a distinct, individual domain of time, place, or pursuit.

As soon as one passes through the gate, the usual temporal parameters disappear. While a few events are scheduled, reservations are easy to make at electronic stations. Clocks are difficult to find, and the functions by which one usually structures time blend into a constant present. Numerous snack bars, cafeterias, and restaurants provide food for all tastes and pocketbooks on any impulse. Restrooms are everywhere and clean. Opportunities for play, purchase, entertainment, excitement, education, and rest are always within easy reach. One can even live in Disney World, since several themed hotels and resorts are located tangentially, connected by pathways and miniature trains. The stress of time and the rigidity of schedules disappear, and one floats along in a pressureless, though eventful, temporal haze.

As one enters a different domain of time, so one lives in another realm of space. The outside world is quite forgotten. Architectural intimidation, so common in industrial societies, does not exist here. No skyscrapers or structures of overpowering mass oppress the visitor. The scale of buildings is comfortably proportionate to the human body and garden areas are all about, so that despite the large numbers of people one never feels claustrophobic. Lines do not seem excessively long. They typically follow a switchback pattern, are hidden by landscaping whenever possible, and are rendered less tedious by settings and backdrops keyed to the upcoming ride or attraction. Because nothing is very high, space is experienced as largely horizontal. Everywhere one has a sense of expansiveness, even without any large, open pedestrian plaza. One's attention is drawn instead to the many local niches and attractions. All this may account for the remarkably benign behavior of its large crowds.

Most people walk everywhere, and this sets the pace of movement. This is not 
burdensome, for frequent garden enclaves provide places of rest and retreat. While Disney World casts its appeal largely to a juvenile audience, it attracts families and people of all ages. Yet in spite of the nature and diversity of its visitors, the level of stress is remarkably low, and loud voices and fast movement are rare. The leisurely pace and serendipitous atmosphere keep one in a state of relaxed anticipation. Yes, there is canned background music, but it is qualitatively better than the canned goods at other markets and effectively blankets the ambient noise. The sound system, moreover, is of high quality and unobtrusive, with its volume low and its speakers hidden in the garden foliage.

\section{The Multiple Realities of Disney World}

Disney World, then, is a comfortable mix of discrete regions, styles, activities, interests. It is interesting to speculate on what makes this mélange successful in luring people there to spend days on end without a feeling of surfeit. The clear division into distinct areas and activities, the gentle pace, the superabundance of easy satisfactions, and an unthreatening atmosphere of fantasy all belie the stresses of ordinary life and encourage feelings of comfort and pleasure. Disney World offers the visitor multiple worlds, from the storybook fantasy of the Magic Kingdom and the futuristic fantasy of Future World, to the idealized cultural environments of World Showcase and the fragmented three-dimensional images of the movie world at Disney-MGM Studios. Disney World is, in fact, a pop postmodern environment. With its heterogeneous profusion of brief distractions and fragmentation of attention into three-minute spots, it is a flowering of our electronic, entertainment culture.

Although this giant collection offers a seemingly endless variety, there is an underlying logic in its order as well as its intent. The multitude of worlds resolves into four kinds: fantasy, adventure, futuristic, and national-cultural. The fantasy environments of Disney World are idealized re-creations which freely use every cliché in the popular imagination. Mickey Mouse, the Haunted Mansion, the Liberty Bell, the Victorian facades of a turn-of-the-century small town, Cinderella, the Mad Hatter's Tea Party, and Snow White are some of the cultural classics or cliches that populate the park. Another of Disney's worlds appears in the adventure 
environments, from the American frontier, the Swiss Family Robinson's treehouse, and a Jungle Cruise, to Caribbean pirate strongholds, space travel simulations, 3D films, and films with wrap-around screens. Its futuristic environments contain Disney World's euphoric presentation of a benign high-tech future dominated by a space travel scenario. Communication, health, transportation, habitat, food, the sea, energy, creativity--the exhibits and language of Future World sing the ideology of endless technological progress.

Cultural environments are the fourth component of Disney World. Across the central lagoon at Epcot Center is World Showcase, eleven national pavilions or rather ethnic enclaves representing Mexico, Norway, China, Germany, Italy, the United States, Japan, Morocco, France, the United Kingdom, and Canada. Each endeavors to convey a sense of its nation and culture through replicas of famous landmarks and indigenous architectural styles, gardens, local crafts and wares, restaurants serving national cuisine, and live performances of traditional arts. An Aztec pyramid, the Eiffel Tower, Katsura Palace, the Venice campanile, the Temple of Heaven, and a Rocky Mountain landscape make many of the pavilions instantly recognizable. "Illuminations," a high-tech light show, music, and fireworks extravaganza above the central lagoon, closes each day at Epcot Center, drawing the darkened pavilions together with laser spotlights and music from different national traditions.

Despite the overwhelming profusion of buildings and events, these many environments share certain characteristics. Most striking to the reflective visitor is the thorough planning, extending to the seemingly spontaneous parades, skits, and other street performances. Visible and invisible controls make these environments so carefree that, despite the crowds and the ceaseless activity, these public spaces never become threatening. We are in a wonderland in which people readily suspend their usual attitude and behavior, and where criticism and controversy never occur.

\section{Disney World as a Postmodern Environment}

This jostling multiplicity of environments actually turns Disney World into a parody of postmodernism. The most salient feature of postmodern architecture, its imaginative combination 
of stylistic elements from a variety of traditional sources, here assumes the hyperbole and fluidity of cartoon time and space. Like postmodern architecture, Disney World presents historicality without being itself historical. Despite a content of real and imaginative histories, it is, in fact, actually ahistorical. History here is idealized and fictionalized, its selections taken from a design book for their entertainment value. The historical replicas here did not develop and age, and they show no signs of the processes of time or the wear of use. Everything is changeless, eternally new, bright, and clean. Authenticity becomes irrelevant and is replaced by satisfaction. Indeed, authenticity must be given a different definition in Disney World's postmodern sense of time. When cartoon and movie characters and events come to "life," one joins them in a different order of reality, a fun loving, carefree world.

Moreover, like so many of the contemporary arts, Disney World is explicitly and intrinsically self-referential, simultaneously referring to itself and its methods as it presents them. Visitors continuously move in and out of both levels, concurrently participating in and learning about them. Some "informational" exhibits are pure fiction, from Mickey Mouse's bed to a tour of the technological future--fantasy about fantasy. Disney World is also culturally self-referential. It provides visitors with a tour of American beliefs about itself and corporate beliefs about technology. Even more, it embodies them.

Like postmodern architecture, Disney World combines disparate styles with a rich complex of allusions and references, and presents them as entertainment. And like postmodern architecture, its order does not lie entirely in its forms but in its meanings and interpretations. Lyotard has argued that the mark of the postmodern lies in putting forward "the unpresentable in presentation itself....[It] searches for new presentations, not in order to enjoy them but in order to impart a stronger sense of the unpresentable."2 Disney World epitomizes this conception of the postmodern, for behind its plethora of presentations lie meanings and beliefs that cannot be shown directly. There could be no more apt subject for interpretation than this, for while Disney

2 J.F. Lyotard, The Postmodern Condition (Minneapolis: University of Minnesota Press, 1984), p.81. 
World is a rich subject, interpretations are multiple and often incompatible, a cognitive analogue of the eclecticism of postmodernism. Yet the very fact that they form an inconclusive order makes Disney World an ideal subject for deconstructive analysis.

\section{Disney World's Multiple Meanings}

Although interpretations multiply freely, they are either descriptive or critical. Of the first, the most obvious sees Disney World as an entertainment park where visitors are encouraged to be carefree and spontaneous. People can be guided by impulse alone without fear of unhappy consequences, for fantasy is the overall motif and every outcome is positive. This is a world of happy make-believe, a place in which ordinary limits do not apply and one can do anything. As an entertainment park Disney World succeeds admirably. It is an enormously large and successful business that has made itself into an institution of American culture with a wide and devoted following, and has become a major destination for foreign visitors, as well. One can also describe Disney World as an educational institution, and many of its attractions make that appeal: The activities and exhibits in Future World cover a wide range of scientific and technological areas, World Showcase is a three-dimensional travelogue, Disney-MGM Studios offers tours of animation and movie sets and studios, while in Magic Kingdom, Liberty Square provides visitors with lessons in American history. Yet behind its joyful surface lies a highly complex and intricately planned operation, for Disney World is a model of high-tech planning and population control. Everything has been thought of to ease and please its large crowds of visitors. Nothing is allowed to tarnish its brilliant image of cleanliness and order, and no trash is ever in sight. An elaborate network of controls regulates all events and activities, and in a supreme gesture of self-referentiality, there is even a tour of the control center.

But this virtuoso technology and manifestly wholesome entertainment and instruction conceal a deep subconscious, metaphorically speaking, which, like its Freudian analogue, is nine-tenths submerged. As a cultural symbol, Disney World is subtly penetrating. Behind its environment of glittering surfaces, its "wilderness of images," to use a phrase of T. S. Eliot, hide disturbing meanings. In numerous ways the park both illustrates and epitomizes kinds of thought 
and practice that characterize the industrial-commercial culture of our period. One wonders how many visitors note the pervasive identification of the corporations sponsoring the giant pavilions that display and laud technology with technology itself and the kind of life it makes possible. And that kind of life is associated with consumption. Disney World, in fact, openly purveys the culture of consumption. It is easy, convenient, and painless to spend money here, for this is the land of consumerism. The very fact that admission to the park entitles one to enter every building and attraction fosters a sense of free entertainment that easily moves out to include the kiosks and shops that stand at every turn, while purchasing Disney Dollars encourages a sense of monetary make-believe.

Disney World is actually a soft-sell environment. While everything seems designed for ease and pleasure, subtle controls extend in every direction, leading to the total manipulation of its visitors, although with disarming gentleness. In fact, Disney World stands, perhaps more than anything else, as a monument to consumer culture. Everything is converted into matter for consumption: national and ethnic traditions, science, technology, education. Even the family is transformed into a unit of consumption. History, too, of science, of technology, of nations, is just another commodity that can be fashioned to meet the requirements of the situation and sold to the public. Entertainment has become Big Business, and the business of Disney World is entertainment. Its product is pleasure and its production is consumption. Eco considers such a place "at once absolutely realistic and absolutely fantastic....Facades [are] presented to us as toy houses and invite us to enter them, but their interior is always a disguised supermarket, where you buy obsessively believing you are still playing." It is what Morawski has called a "consumerist fairyland. No codes and no norms deserve any serious attention as they cancel each other." Spectacles produce excitement and a pleasant confusion, while their hidden messages, buried in the casual occurrences of mass culture, effectively take over. ${ }^{3}$

3 Umberto Eco, "Travels in Hyperreality," in Travels in Hyperreality (New York: Harcourt Brace Jovanovich, 1986), p. 43. Stefan Morawski, "On the Subject of and in Post-Modernism," British Journal of Aesthetics, 32/1 (January 1992), 57. 
What we have here is actually a new colonialism, a corporate colonialism over the consumer, a cultural colonialism of the high tech nations over the third world. The culture of consumption has appropriated the past, ethnic practices, even science, and all in the name of corporate interests such as those that designed and operate nearly all the major pavilions in Future World. The social consequences of this are alarming, for despite beneficent, indulgent appearances, Disney World is in practice a totalitarian environment. One encounters no scowling face, no disagreement, no dissent, differences, or alternatives to the omnipresent good nature and good cheer. The Disney Corporation has, moreover, very strict hiring guidelines. Disney World hires only about one in every ten individuals interviewed. Euro Disneyland, outside of Paris, created a good deal of animosity by requiring its employees to display smiling faces, a custom more American than European. The fact that everything is planned so successfully means in practice that everything is controlled, and controlled in the interests of a single optimistic message. Many of the exhibits are badly out of date, seemingly stuck in the 1970s. Most show little environmental consciousness, no questioning of faith in science, and no acknowledgement of alternative lifestyles or of Eastern religion, to name a few absent alternatives.

Moreover, Disney World is no aberrant development. Not only are the Disney parks models for theme parks everywhere, but the model has been extended to entire nations, from considering Mexico as the Third World theme park for Americans, rural England as a theme park for escaping urban dwellers, and Britain as a giant rain theme park, to a proposal to market the entire United States as a theme park for visiting Europeans. Moreover, the theme park can create history by influencing our beliefs about the past. ${ }^{4}$ To turn the world into a collection of theme

${ }_{4}$ Bob Shacochis, "In Deepest Gringolandia," ㄹarpers, Vol. 279, No. 1670 (July 1989), 42-50; Alun Howkens, "Peace of the Country," New Statesman and Society, Vol. 2, No. 61 (Aug. 4, 1989), 12-13; Alice Thomas Ellis, "Crumbling Urns," Spectator, Vol. 261, No. 8350 (Jul 23, 1988), 34-35. In "The Influence of a Multi-Theme Park on Cultural Beliefs as a Function of Schema Salience: Promoting and Undermining the Myth of the Old West," Donna Morganstern and Jeff Greenberg show how theme park visits can influence beliefs about the past. Journal of Applied Social Psychology, Vol. 
parks, a future some fear, is to conquer the very planet, using the smile as the ultimate weapon to subdue a mass population with good humor.

This is an environment, then, in which nothing is as it appears to be. Spectacular in scale and brilliant in execution, Disney World is a "masterpiece of falsification. "What it sells is, indeed, goods, but genuine merchandise, not reproductions. What is falsified is our will to buy, which we take as real, and in this sense Disneyland is really the quintessence of consumer ideology." ${ }^{5}$ Not only does Disney World run its subject matter past a distorting mirror; it actually contains levels of falseness, for even when something is itself authentic, its context renders it false. The architectural designs in World Showcase, for example, are accurate replicas of indigenous architectural styles. Yet they are merely surfaces, authentic facades. Behind each is another tourist shop, a snack bar, or nothing at all. What is authenticity in such a setting? Is there such a thing as authenticity any more? ${ }^{6}$

Other purposes hide behind everything. Disney World represents itself as the full flowering of the modernist ethos, with its confidence in a future guided by scientific imagination toward a technological utopia. But the contrast is vivid between the use of that technology and the kind of experience visitors have. As we are pleasantly lulled into accepting the modernist ideology of Disney World, we are subjected to a level of exploitation virtuosic in its sophistication and insidious in its effects: the total cooptation of our beliefs and purposes and their ultimate absorption into the credit card culture of consumption.

The juxtaposition of futuristic visions with historical and fictional experiences actually contradicts and subverts a key modernist element, the idea of steady, limitless scientific progress. Unidirectional time is abandoned. One inhabits a timeless realm in which everything is constantly

\section{8 (June 1988), 584-596.}

${ }^{5}$ Eco, p. 43.

${ }^{6}$ See Christopher Frayling, "Themes Like Old Times," Punch, Vol 298, Issue 7774 (Jan. 26, 1990), 30-33. 
available and the future lies before us as eternal beneficence. There is no acknowledgement that technology has consequences and that many of the our planet's present problems, from acid rain and the depletion of the ozone layer to overpopulation, nuclear waste, and modern warfare, are the largely unplanned or unwanted results of industrial technology. And history, its hard pain painted over by bland romanticism, becomes sentimental entertainment.

Even more, the universal scope of the theme park undermines our grasp of reality. Not only are there multiple realities here of fiction, fantasy, science, geography, history, and nationality, each with its own special claim: The distortion of their content, the blurring of distinctions among them, the deliberate confusion of their modes, and the omission of everyday economic reality ingeniously exploits what Disney World purportedly honors: children, by turning the world into a cartoon; the family, by promoting social stereotypes and identifying the family with a lifestyle of consumption; ethnic traditions, by transforming them into consumable curiosities and collectibles instead of genuine practices integral to their cultures; science, by portraying it as inevitably successful and invariably benevolent; technology, by ascribing to it a limitless capacity for improving life by inventing consumables that are always desirable.

These different realities do not only form a heterogeneous mass; their order is uncertain. The national enclaves of World Showcase, for example, offer ethnic realities within another reality--Epcot Center, within another reality--Disney World, within yet another reality--themed hotels and resorts, within still another reality--Orlando. Yet does any of these realities predominate? One might be tempted to say the "outer world" of Orlando. Yet we are hardly aware of Orlando at all and most visitors encounter the city only from the super highway or the airport. Furthermore, the immediacy of one's present location is inevitably the most forceful, making it constantly unclear which end is up, as we move from one place to another. This is true not only inside the theme park; we carry such confusion away with us, just as we whistle a tune after the show is over or have uneasy dreams after watching a horror movie. Disney-MGM Studios further epitomizes this jumbled juxtaposition of worlds, this cultural cubism. Its animation studios and movie sets show how film reality is fabricated out of fragments, and the park itself encourages a breakdown of the difference between the movie illusion and actual places and 
events. Things are equally real and equally hollow. Is there a cultural schizophrenia at work here? This disintegration of reality structure is what Marin has called "a degenerate utopia...at once absolutely realistic and absolutely fantastic." 7

Most of Disney World's multiple meanings, moreover, convincing yet not always compatible, are not delivered directly but gain force precisely through their indirection. Perhaps it is not just that they are not presented immediately but that they cannot be. This is Disney World's postmodernism in Lyotard's sense, its presentation of the unpresentable. What are the hidden meanings, the subliminal forces at work here? Do we begin to discover them as we peel off the smiles? Lyotard claims further that "modern aesthetics is an aesthetic of the sublime, though a nostalgic one. It allows the unpresentable to be put forward only as the missing contents; but the form, because of its recognizable consistency, continues to offer to the reader or viewer matter for solace and pleasure." 8 By presenting the unpresentable on a magnitude hitherto inconceivable and perhaps beyond rational comprehension, Disney World, one could argue, represents the sublime in this postmodern age. The theme park is at the same time the sublimation of commercial culture and the desublimation of the sublime. Disney World has become, in fact, our monument to the sublime, its most salient expression at the culmination of the twentieth century. Yet can magnitude without elevation attain the sublime?

\section{The Normative Significance of Disney World}

I had originally thought to end this essay with an inconclusiveness appropriate to the topic. Yet deconstructing Disney World shows that the dilemma of multiple, incompatible interpretations and the impossibility of resolving them does not obliterate normative judgment. On the contrary, this discussion stands as an argument against moral indecisiveness. For normative judgment is built into the very pursuit of understanding and this last critique embodies a powerful moral condemnation. It is true that one can see Disney World as both a fairyland for family

\footnotetext{
7 Quoted in Eco, p. 43.
}

8 Lyotard, The Postmodern Condition, p. 81. 
entertainment and an enormously complex and sophisticated work of popular art. Surely these mark its positive contribution to popular culture. On the other hand, our analysis reveals the most sophisticated and comprehensive instance in our time of the subversion by corporate interests of personal motives, social institutions, and public values. Disney World stands as a megamonument to the commodification of culture. Can we determine which values in this heterogeneous mix are preeminent? Does a deconstructive analysis carry us beyond the coexistence of multiple, mutually incompatible interpretations to a moral conclusion?

The case for Disney World is obvious. In its favor stands the mass audience of the theme park. For its avid followers, regular visits are a high point of personal and family life, and they happily spend vast sums for what they perceive to be full value. Who could quarrel with family fun and healthy popular art? Yet the positive case can be countered in more than one way. Against the elaborate serendipity of Disney World are the witnesses to the simple, unencumbered life, from the ancient Stoics to E. F. Schumacher, Scott Nearing, and the contemporary rediscoverers of Buddhism in the West. To find the universe in one's backyard, as Thoreau once urged, suggests an economy directed, not toward the consumption of luxuries but toward enlightenment, the cultivation of aesthetic sensibility, and a deepening of moral experience that leads us to recognize the ultimacy of life and the omnipresence of the sacred.

More compelling than this alternative, however, is the unsettling picture that presents itself when we look closely at what the theme park is and what it does. As we begin to detect the falseness and manipulation that underlie its pleasant gloss, we are led to condemn its empty pleasures as soporific and exploitative. The Socratic tradition that forsakes satisfaction for understanding is a perennially sobering influence in matters such as this. While we cannot appeal to a simple hierarchy of values, we do have in this instance a clear choice between the dissatisfactions of a Socrates and the satisfactions of a fool, to recall Mill. The determination of value here lies in having experienced both. ${ }^{9}$ Once we recognize the motives and interests that underlie the theme park, can we ever again find satisfaction in its joyful surfaces?

9 John Stuart Mill, Utilitarianism (Indianapolis: Bobbs-Merrill, 1957), p. 14 (Ch. II). 
What we approach through postmodernism is a sense of things that has been emerging slowly throughout the long and difficult century we are now concluding: the realization that the tradition of clear resolutions and final certainties distorts the facts of irresolvable difference, limited understanding, and a residual pluralism of truths and values. Dewey's recognition that "the quest for certainty" is misdirected helped inaugurate a different sense of knowledge, one not governed by the goal of complete, permament, and univocal truth but rather of truths in the making, provisional, multiple nodes in a constantly altering web of knowledge governed by changing conditions, needs, and activities. ${ }^{10}$ Yet realizing this does not abandon us to intellectual fragmentation and cognitive chaos. It calls rather for a conceptual landscape vastly different from the modernist ideal of an unequivocal order revealed by "the light of reason." We need something akin to what Merleau-Ponty termed "the good dialectic," "capable of differentiating and of integrating into one sole universe double or even multiple meanings....because it envisages without restriction the plurality of the relationships and what has been called ambiguity."11

It means admitting value, too, into an enlarged cognitive realm. Values cannot be relegated to the shadowy region of the emotive, as the positivists would have it. We have come to realize that the normative pervades all experience, cognitive as much as any other. No human activity, scientific or artistic, can breathe air that is value neutral. Value suffuses the human presence and whatever we touch has a normative dimension. That is why an aesthetic analysis of Disney World that began with an attempt at pure description ended with moral judgment. This does not create an unwelcome complication in the knowledge process; it recognizes that another facet on the complex jewel of human understanding has been glowing all along. We find ourselves returning, in this humanized landscape of understanding, to the insight of our classical

10 John Dewey, The Quest for Certainty: A Study of the Relation of Knowledge and Action (New York: Minton, Balch \& Co., 1929.

11 Maurice Merleau-Ponty, The Visible and the Invisible (Evanston: Northwestern University Press, 1968), pp. 91, 94. 
forebears that truth and value are inseparable, but we must couple this with the recognition by contemporary science and philosophy that these are invariably contextual and contingent.

Such an approach offers a direction, at the close of the post-modern age, that may rescue us from the morass into which an overly simple epistemology has sunk us. It suggests that multiple interpretations do not all have equal weight, that postmodernism requires deconstruction, and that its deconstruction leads to a conclusion somewhat less destructive than indefiniteness and less autocratic than "Truth." This aesthetic analysis of Disney's worlds, by showing how realities are created and subverted, confronts us with the pervasiveness of the normative and the inseparability of the moral and the aesthetic. The challenge of our time is to reform knowledge and value in a way that is pluralistic and open-ended, and yet provides the basis for both decision and action. Such restructuring is an inevitable consequence of the inadequacies of the old millennium and the necessary precondition for the foundation of a new. 
NOTES 